Article

\title{
Clinical Characteristics and Predictors of Mortality in Critically Ill Influenza Adult Patients
}

\author{
Jui-Chi Hsu ${ }^{1}$, Ing-Kit Lee ${ }^{1,2, *}$, Wen-Chi Huang ${ }^{1}$, Yi-Chun Chen ${ }^{1}$ and Ching-Yen Tsai ${ }^{1}$ \\ 1 Division of Infectious Diseases, Department of Internal Medicine, Kaohsiung Chang Gung Memorial \\ Hospital, Kaohsiung 833, Taiwan; b9602048@cgmh.org.tw (J.-C.H.); heteyland@cgmh.org.tw (W.-C.H.); \\ sonice83@cgmh.org.tw (Y.-C.C.); greenswallow822@yahoo.com.tw (C.-Y.T.) \\ 2 Department of Internal Medicine, Chang Gung University Medical College, Tao-Yuan 330, Taiwan \\ * Correspondence: leee@cgmh.org.tw
}

Received: 7 March 2020; Accepted: 7 April 2020; Published: 9 April 2020

check for updates

\begin{abstract}
Severe influenza is associated with high morbidity and mortality. The aim of this study was to investigate the factors affecting the clinical outcomes of critically ill influenza patients. In this retrospective study, we enrolled critically ill adult patients with influenza at the Kaohsiung Chang Gung Memorial Hospital in Taiwan. We evaluated the demographic, clinical, and laboratory findings and examined whether any of these measurements correlated with mortality. We then created an event-based algorithm as a simple predictive tool using two variables with statistically significant associations with mortality. Between 2015 and 2018, 102 critically ill influenza patients (median age, 62 years) were assessed; among them, 41 (40.1\%) patients died. Of the 94 patients who received oseltamivir therapy, 68 (72.3\%) began taking oseltamivir $48 \mathrm{~h}$ after the onset of illness. Of the 102 patients, the major influenza-associated complications were respiratory failure $(97 \%)$, pneumonia (94.1\%), acute kidney injury (65.7\%), adult respiratory distress syndrome (ARDS) (51\%), gastrointestinal bleeding (35.3\%), and bacteremia (16.7\%). In the multivariate regression model, high lactate levels, ARDS, acute kidney injury, and gastrointestinal bleeding were independent predictors of mortality in critically ill influenza patients. The optimal lactate level cutoff for predicting mortality was $3.7 \mathrm{mmol} / \mathrm{L}$ with an area under curve of 0.728 . We constructed an event-associated algorithm that included lactate and ARDS. Fifteen (75\%) of 20 patients with lactate levels $3.7 \mathrm{mmol} / \mathrm{L}$ and ARDS died, compared with only $1(7.7 \%)$ of 13 patients with normal lactate levels and without ARDS. We identified clinical and laboratory predictors of mortality that could aid in the care of critically ill influenza patients. Identification of these prognostic markers could be improved to prioritize key examinations that might be useful in determining patient outcomes.
\end{abstract}

Keywords: severe influenza; pneumonia; acute respiratory distress syndrome; lactate; mortality

\section{Introduction}

Influenza is an acute viral respiratory infection caused by different types of influenza viruses: influenza A, B, and C [1]. Influenza A subtypes H1N1, H3N2, and influenza B are the most common causes of human influenza [1]. The illness is usually mild and characterized by a sudden onset of fever, cough, sore throat, runny nose, headache, myalgia, and malaise [1]. However, the virus can cause severe illness or even death, especially in high-risk individuals such as young children, the elderly, patients with certain comorbid chronic diseases, and immunocompromised patients [2,3]. Annually, the World Health Organization estimated that global influenza epidemics result in 3 to 5 million cases of severe illness and 290,000 to 650,000 deaths [4,5]. In 2009, a swine-origin influenza A (pandemic 2009 A/H1N1; pdm09 A/H1) emerged and rapidly caused a global pandemic [6]. Remarkably, from 
12 April 2009 to 10 April 2010, there were 60.8 million cases and 12,469 deaths in the United States due to $\mathrm{pdm} 09 \mathrm{~A} / \mathrm{H} 1$ [7].

Severe complicated influenza has a significantly high mortality and morbidity [8,9]. Secondary bacterial pneumonia and acute respiratory distress syndrome (ARDS) are some of the common pulmonary complications of influenza, often followed by grave outcomes [10]. In addition to pulmonary complications, extra-pulmonary complications such as meningoencephalitis, myocarditis, and rhabdomyolysis have also been reported to be associated with either influenza A or B [11-13]. While early antiviral therapy may reduce complications of influenza [14-16], the majority of patients tend to delay seeking medical care and timely diagnosis, leading to the subsequent development of influenza-associated complications, particularly in the elderly and those with comorbid illnesses. Hence, key clinical data are crucial pieces of information that can help clinicians deliver the necessary management to critically ill influenza patients in a timely manner. In the present study, we reviewed the entire clinical course and laboratory data of critically ill patients with influenza and then explored the risk factors independently associated with death as well as constructed a valuable event associated algorithm to help in the assessment of risk of death.

\section{Methods}

\subsection{Study Design and Patients}

We retrospectively studied all critically ill adult patients (aged $\geq 18$ years) with laboratoryconfirmed influenza infection admitted between 2015 and 2018, at the Kaohsiung Chang Gung Memorial Hospital, a 2700-bed primary care and tertiary referral medical center that included 5 adult medical and 4 surgical intensive care units (ICUs) in Taiwan. Included critically ill influenza patients were those admitted to an ICU, or those with complications of lower respiratory tract infection and/or multiorgan failure, or those requiring mechanical ventilation during hospitalization. Individuals were excluded from the study if they are $<18$ years of age; if they are treated as outpatients; or if they had mild flu-like symptoms. Confirmation of influenza virus infection required a positive finding in the respiratory specimen (nasopharyngeal swab and/or pharyngeal swab) by one or more of the following methods: rapid influenza diagnostic test (Formosa One Sure Flu A/B Rapid Test $\mathrm{Kit}$ ), isolation of the virus in tissue-cell culture (Madin-Darby canine kidney (MDCK) cell line), or reverse-transcriptase-polymerase chain reaction (RT-PCR) (QiAamp Viral RNA Mini Kit; TAIGEN Bioscience Corporation, Taiwan). The choice of diagnostic test (rapid influenza diagnostic test, virus isolation or RT-PCR) for confirming influenza was based on the individual physicians' judgment.

\subsection{Data Collection and Definitions}

A standardized form for clinical data collection was designed. The data were mainly retrieved from the hospital's electronic medical records and were supplemented by a secondary manual search. The following data were collected: demographic characteristics, underlying medical conditions, clinical signs and symptoms, antiviral treatment course (oseltamivir or peramivir therapy), results of laboratory tests and radiography findings at the time of presentation and during the entire clinical course, in-hospital complications, and fatality.

Acute respiratory failure was defined as arterial partial pressure of oxygen $\left(\mathrm{PaO}_{2}\right)<60 \mathrm{mmHg}$ in ambient air, or tachypnea $>30 / \mathrm{min}$. ARDS was defined as acute respiratory distress characterized by bilateral pulmonary consolidation and severe hypoxemia $\left(\mathrm{PaO}_{2} /\right.$ Fraction of inspired oxygen ratio $<300 \mathrm{mmHg}$ ) in the absence of evidence for cardiogenic pulmonary edema [17]. Fulminant hepatitis meant alanine aminotransferase levels (ALT) greater than $16.6 \mu \mathrm{kat} / \mathrm{L}$. Acute kidney injury was defined as a rapid increase in the serum creatinine level to $>44.2 \mu \mathrm{mol} / \mathrm{L}$ compared with that at presentation. Rhabdomyolysis was defined as a five-fold increase in the serum concentrations of creatine phosphokinase above the upper limit of the normal range (reference value, 0.2-2.2 $\mu \mathrm{kat} / \mathrm{L}$ ), with $>95 \%$ creatine phosphokinase-muscle fraction. Meningoencephalitis was defined as an altered 
mental status, fulfilling at least 2 of the following criteria: (1) fever, (2) seizure, (3) focal neurologic signs, (4) abnormality of cerebrospinal fluid, (5) neuroimaging suggestive of encephalitis, and (6) abnormal findings on electroencephalography consistent with encephalitis [18]. A galactomannan cutoff optical density index of $>0.5$ was used to define positivity for serum and bronchoalveolar lavage samples $[19,20]$. Mortality was defined as death occurring during the hospital stay for influenza.

\subsection{Statistical Analysis}

To analyze the predictors of mortality among critically ill influenza patients, we initially compared demographic, clinical characteristics, and laboratory findings as well as complications of survivors and nonsurvivors using Fisher's exact test for categorical variables and Mann-Whitney $U$ test for numerical variables. The differences were considered significant at $p<0.05$. Significant variables in the univariate analyses were entered into a multivariate logistic regression model to identify independent predictors of mortality in critically ill influenza patients. We used receiver operating characteristic curves (ROC) to select cutoff points for independent numerical predictors according to visual assessment of the highest sensitivity and specificity. We then created an event-based algorithm as a simple predictive tool using 2 variables with statistically significant associations with mortality ( $p$ value less than or equal to 0.001) in the multivariate model. Data were entered and analyzed using the Statistical Package for the Social Sciences statistical software (version 19.0; SPSS Inc., Chicago, IL, USA).

\section{Results}

\subsection{Patient Characteristics}

In total, 102 critically ill patients (97\% in medical ICUs and 3\% in surgical ICUs) comprising 62 men and 40 women, with a median age of 62 years with laboratory-confirmed influenza virus infection were assessed. The median time from illness onset to hospital presentation was three days (range, 1-14).

Among the 102 patients, three did not receive antiviral therapy (either oseltamivir or peramivir). Of the 99 patients who received antiviral therapy, 89 patients received oseltamivir and five received peramivir; five patients received both oseltamivir and peramivir during their hospitalization. Of the 94 patients who received oseltamivir therapy, 68 (72.3\%) began taking oseltamivir $48 \mathrm{~h}$ after the onset of illness. Among the 10 patients who received peramivir, $60 \%$ received antiviral therapy $48 \mathrm{~h}$ after the onset of symptoms. Among 102 patients, influenza A virus was detected in $77(75.5 \%)$ patients $(33.3 \%$ for pdm09 A/H1, 7.8\% for H3N2 and 28.4\% for untypable influenza A), influenza B virus in $24(23.5 \%)$, and concurrent influenza A (untypable) and influenza B in $1(0.9 \%)$. The clinical characteristics of the included patients are summarized in Tables 1 and 2. 
Table 1. Characteristics and diagnostic methods of patients with severe influenza.

\begin{tabular}{|c|c|c|c|c|}
\hline & Overall $(n=102)$ & Survivors $(n=61)$ & Nonsurvivors $(n=41)$ & $p$ Value \\
\hline \multicolumn{5}{|l|}{ Demographic and Clinical Features } \\
\hline Age, years, median (range) & $62(24-93)$ & $65(24-92)$ & $61(24-93)$ & 0.186 \\
\hline Age group, $N(\%)$ & & & & 0.068 \\
\hline $20-49$ year & $20(19.6)$ & $11(18)$ & $9(22)$ & \\
\hline $50-64$ & $38(37.3)$ & $19(31.1)$ & $19(46.3)$ & \\
\hline$\geq 65$ year & $44(43.1)$ & $31(50.8)$ & $13(31.7)$ & \\
\hline Female gender, $N(\%)$ & $40(39)$ & $23(37.7)$ & $17(41.5)$ & 0.836 \\
\hline Body mass index, median (range) & $23.25(16.7-37.8)(n=86)$ & $23.8(16.7-35.7)(n=55)$ & $22.7(17.8-37.8)(n=31)$ & 0.583 \\
\hline \multicolumn{5}{|l|}{ Underlying condition, $N(\%)$} \\
\hline Bronchial asthma & $7(6.9)$ & $4(6.6)$ & $3(7.3)$ & $>0.99$ \\
\hline Hypertension & $56(54.9)$ & $38(62.3)$ & $18(43.9)$ & 0.073 \\
\hline Type 2 diabetes mellitus & $45(44.1)$ & $28(45.9)$ & $17(41.5)$ & 0.689 \\
\hline Chronic kidney disease & $16(15.7)$ & $13(21.3)$ & $3(7.3)$ & 0.094 \\
\hline End stage renal disease & $9(8.8)$ & $5(8.2)$ & $4(9.8)$ & $>0.99$ \\
\hline Chronic obstructive pulmonary disease & $8(7.8)$ & $7(11.5)$ & $1(2.4)$ & 0.139 \\
\hline Liver cirrhosis & $6(5.9)$ & $3(4.9)$ & $3(7.3)$ & 0.682 \\
\hline qSOFA, median (range) & $1(0-3)(n=99)$ & $1(0-3)(n=60)$ & $1(0-2)(n=39)$ & 0.906 \\
\hline SOFA, median (range) & $6(2-16)(n=59)$ & $6(2-16)(n=34)$ & $7(3-14)(n=25)$ & 0.263 \\
\hline Times from illness onset to hospital presentation, days, median (range) & $3(1-14)$ & $2(1-10)$ & $3(1-14)$ & 0.414 \\
\hline Times from illness onset to fatality, day, median (range) & - & - & $18.5(2-53)$ & - \\
\hline Hospital length of stay, days, median (range) & $23(1-107)$ & $32(2-107)$ & $14(1-53)$ & $<0.001$ \\
\hline Stay in intensive care unit, $N(\%)$ & $98(96.1)$ & $60(98.3)$ & $38(92.7)$ & 0.177 \\
\hline Use antibiotic at presentation, $N(\%)$ & $100(98)$ & $60(98.4)$ & 40 (97.6) & $>0.99$ \\
\hline Use oseltamivir, $N(\%)$ & $94(92.2)$ & $56(91.8)$ & $38(92.7)$ & $>0.99$ \\
\hline Use oseltamivir $\geq 48 \mathrm{~h}$ after onset of illness, $\mathrm{N} /$ total $N(\%)$ & $68 / 94(72.3)$ & $39 / 56(69.6)$ & $29 / 38(76.3)$ & 0.639 \\
\hline Use peramivir, $N(\%)$ & $10(9.8)$ & $8(13.1)$ & $2(4.9)$ & 0.793 \\
\hline Use peramivir $\geq 48 \mathrm{~h}$ after onset of illness, $N /$ total $N(\%)$ & $6 / 10(60)$ & $5 / 8(62.5)$ & $1 / 2(50)$ & $>0.99$ \\
\hline Use statin, $N(\%)$ & $21(20.6)$ & $14(23)$ & $7(17.1)$ & 0.610 \\
\hline Use metformin, $N(\%)$ & $17(16.7)$ & $13(21.3)$ & $4(9.8)$ & 0.177 \\
\hline Use vasopressor & $44(43.1)$ & $15(24.6)$ & $29(70.7)$ & $<0.001$ \\
\hline \multicolumn{5}{|l|}{ Diagnostic methods for influenza, $N /$ total $N(\%)$} \\
\hline Positive of influenza rapid test & $51 / 93(54.8)$ & $34 / 56(60.7)$ & $17 / 37(45.9)$ & - \\
\hline Positive of RT-PCR for influenza & 94/98 (95.9) & $59 / 61(96.7)$ & $35 / 37(94.6)$ & - \\
\hline Positive of throat influenza viral culture & $37 / 95(38.9)$ & 23/59 (39) & $14 / 36(38.9)$ & - \\
\hline \multicolumn{5}{|l|}{ Influenza virus subtype, $N(\%)$} \\
\hline Influenza A & $77(75.5)$ & $44(72.1)$ & $33(80.5)$ & 0.360 \\
\hline pdm 09 H1N1 & $34(33.3)$ & $23(37.7)$ & $11(26.8)$ & 0.290 \\
\hline $\mathrm{H} 3 \mathrm{~N} 2$ & $8(7.8)$ & $7(11.4)$ & $1(2.4)$ & 0.139 \\
\hline Untypable A & $29(28.4)$ & $13(21.3)$ & $16(39)$ & 0.073 \\
\hline Influenza B & $24(23.5)$ & $16(26.2)$ & $8(19.5)$ & 0.483 \\
\hline Concurrent influenza $\mathrm{A}^{\mathrm{a}}$ and $\mathrm{B}$ & $1(0.9)$ & $1(1.6)$ & 0 & $>0.99$ \\
\hline
\end{tabular}

RT-PCR, Reverse transcription-polymerase chain reaction; qSOFA, quick Sequential Organ Failure Assessment. ${ }^{a}$ Untypable influenza A. 
Table 2. Symptom/signs of patients with severe influenza.

\begin{tabular}{ccccc}
\hline $\begin{array}{c}\text { Symptom/Sign at } \\
\text { Presentation }\end{array}$ & Overall $(\boldsymbol{n = 1 0 2 )}$ & Survivors $(\boldsymbol{n}=\mathbf{6 1 )}$ & Nonsurvivors $(\boldsymbol{n}=\mathbf{4 1 )}$ & $\boldsymbol{p}$ Value \\
\hline Fever & $81(79.4)$ & $48(78.7)$ & $33(80.5)$ & $>0.99$ \\
Rhinorrhea & $8(7.8)$ & $3(4.9)$ & $5(12.2)$ & 0.262 \\
Cough & $85(83.3)$ & $49(80.3)$ & $35(85.4)$ & 0.602 \\
Sore throat & $8(7.8)$ & $5(8.2)$ & $3(7.3)$ & $>0.99$ \\
Malaise & $24(23.5)$ & $17(27.9)$ & $7(17.1)$ & 0.241 \\
Muscle pain & $17(16.7)$ & $10(16.4)$ & $3(7.3)$ & 0.233 \\
Headache & $5(4.9)$ & $2(3.3)$ & $3(7.3)$ & 0.389 \\
Vomiting/nausea & $6(5.9)$ & $5(8.2)$ & $1(2.4)$ & 0.397 \\
Diarrhea & $2(2)$ & $1(1.6)$ & $1(2.4)$ & $>0.99$ \\
Abdominal pain & $2(2)$ & $1(1.6)$ & $1(2.4)$ & $>0.99$ \\
Chest pain & $8(7.8)$ & $5(8.2)$ & $3(7.3)$ & $>0.99$ \\
Skin rash & $1(1)$ & $1(1.6)$ & 0 & $>0.99$ \\
Altered consciousness & $16(15.7)$ & $11(18.0)$ & $5(12.2)$ & 0.581 \\
Seizure & $3(2.9)$ & $2(3.3)$ & $1(2.4)$ & $>0.99$ \\
Dyspnea & $87(85.3)$ & $51(83.6)$ & $36(87.8)$ & 0.776 \\
\hline
\end{tabular}

Data expressed as number (\%).

\subsection{Laboratory Testing}

The median white blood cell and platelet counts on admission were $7.9 \times 10^{9} / \mathrm{L}$ and $156.5 \times 10^{9} / \mathrm{L}$, respectively. Regarding the laboratory data during hospitalization, the median highest white blood cell and platelet counts and creatinine, ALT, creatine kinase, C-reactive protein, and lactate concentrations were $16.8 \times 10^{9} / \mathrm{L}, 101.5 \times 10^{9} / \mathrm{L}, 183 \mu \mathrm{mol} / \mathrm{L}, 1.5 \mu \mathrm{kat} / \mathrm{L}$ (96 patients with data available), $5.5 \mu \mathrm{kat} / \mathrm{L}$ (35 patients with data available), $213.6 \mathrm{mg} / \mathrm{L}$ (100 patients with data available), and $3.1 \mathrm{mmol} / \mathrm{L}$ (90 patients with available data), respectively. Five (21.7\%) of the 23 patients with available data showed serum galactomannan index of $>0.5$. Six patients underwent bronchoscopy and two had bronchoalveolar lavage fluid galactomannan index of 5.09 and 5.57 with fatal outcomes. Stenotrophomonas maltophilia was isolated from bronchoalveolar lavage specimen in one patient. Urinary Streptococcus antigen was detected in 3 of the 41 patients with available data. The laboratory characteristics of the included patients are shown in Table 3.

\subsection{Complications}

Table 4 shows the in-hospital complications of the patients during the entire clinical course. The five common complications were respiratory failure (97\%), pneumonia $(94.1 \%)$, acute kidney injury $(65.7 \%)$, ARDS (51\%), and gastrointestinal bleeding (35.3\%). Of 59 patients with data available, the median Sequential Organ Failure Assessment score was 6 (range, 2-16). All of the 102 patients were required to be mechanically ventilated, and among them, $90(88.2 \%)$ were ventilated invasively and 12 $(11.7 \%)$ noninvasively. The median time from illness onset to acute respiratory failure was four days (range, 1-27). Inotropes or vasopressors were used in 44 (43.1\%) patients. Ninety-eight (96.1\%) patients were admitted to the ICU. Four patients did not admit to ICU; of these, three patients died before ICU admission and the other one improved tachypnea after managed by noninvasive ventilation. 
Table 3. Laboratory characteristics of patients with severe influenza.

\begin{tabular}{|c|c|c|c|c|}
\hline Variable & Overall $(n=102)$ & Survivors $(n=61)$ & Non-survivors $(n=41)$ & $p$ \\
\hline \multicolumn{5}{|l|}{ Laboratory Data at Presentation } \\
\hline WBC, $\left(\times 10^{9} / \mathrm{L}\right)$, median (range) & $7.9(0.5-178)$ & $8.7(2.1-27.9)$ & $7(0.5-178)$ & 0.921 \\
\hline Platelet count, $\left(\times 10^{9} / \mathrm{L}\right)$, median (range) & $156.5(4-641)$ & $156(60-641)$ & $158(4-365)$ & 0.407 \\
\hline Hemoglobin, $(\mathrm{g} / \mathrm{L})$, median (range) & $123(72-180)$ & $123(75-180)$ & $123(72-165)$ & 0.309 \\
\hline Proportion of hematocrit, median (range) & $0.36(0.21-0.51)$ & $0.37(0.23-0.51)$ & $0.36(0.21-0.5)$ & 0.785 \\
\hline BUN, $(\mathrm{mmol} / \mathrm{L})$, median (range) & $7.7(2.1-39.2)$ & $7.9(2.1-39.2)$ & $7.5(2.1-35.3)$ & 0.521 \\
\hline Creatinine, $(\mu \mathrm{mol} / \mathrm{L})$, median (range) & $88.4(43.3-1502.8)$ & $114.9(44.2-1502.8)$ & $114.9(53-1105)$ & 0.771 \\
\hline AST, $(\mu \mathrm{kat} / \mathrm{L})$, median (range) & $1(0.2-65.5)(n=98)$ & $0.9(0.2-40.2)(n=59)$ & $1.1(0.2-65.5)(n=39)$ & 0.619 \\
\hline ALT, ( $\mu$ kat/L), median (range) & $0.5(0.1-50)(n=96)$ & $0.5(0.1-50)(n=60)$ & $0.6(0.1-15.3)(n=36)$ & 0.691 \\
\hline $\mathrm{CRP},(\mathrm{mg} / \mathrm{L})$, median (range) & $127(0.4-1377)(n=100)$ & $71.4(0.4-380)(n=59)$ & $155.1(1.3-1377)$ & 0.079 \\
\hline Creatine kinase, $(\mu \mathrm{kat} / \mathrm{L})$, median (range) & $5.4(0.2-248.5)(n=35)$ & $5.7(0.2-198.5)(n=20)$ & $290(4.9-248.5)(n=15)$ & 0.542 \\
\hline LDH, $(\mu \mathrm{kat} / \mathrm{L})$, median (range) & $8.4(2.9-149.4)(n=28)$ & $6.7(2.9-149.4)(n=16)$ & $11.2(4.8-94.6)(n=12)$ & 0.174 \\
\hline Myoglobin, (nmol/L), median (range) & $12.7(0.003-289.5)(n=37)$ & $6(0.003-289.5)(n=19)$ & $26.3(5-252.4)(n=18)$ & 0.010 \\
\hline Troponin-I, ( $\mu \mathrm{g} / \mathrm{L})$, median (range) & $0.06(0.01-80)(n=95)$ & $0.06(0.01-15.9)(n=56)$ & $0.05(0.01-80)(n=39)$ & 0.447 \\
\hline CK-MB, $(\mu \mathrm{kat} / \mathrm{L})$, median (range) & $0.06(0.006-5.12)(n=84)$ & $2.9(0.05-1.2)(n=49)$ & $0.1(0.01-5.1)(n=35)$ & 0.013 \\
\hline Lactate, (mmol/L), median (range) & $1.8(0.7-21.1)(n=90)$ & $1.7(0.9-14.9)(n=54)$ & $2.0(0.7-21.1)(n=36)$ & 0.840 \\
\hline \multicolumn{5}{|l|}{ Laboratory Data during Hospitalization } \\
\hline Highest WBC, $\left(\times 10^{9} / \mathrm{L}\right)$, median (range) & $16.8(1.9-187.6)$ & $15.8(5.2-36.1)$ & $19.6(1.9-187.6)$ & 0.037 \\
\hline Nadir platelet count, $\left(\times 10^{9} / \mathrm{L}\right)$, median (range) & $101.5(4-311)$ & $113(16-311)$ & $68(4-271)$ & 0.005 \\
\hline Highest BUN, (mmol/L), median (range) & $19.8(2.1-94)$ & $14.6(3.9-94)$ & $25.3(2.1-80.7)$ & 0.055 \\
\hline Highest creatinine, $(\mu \mathrm{mol} / \mathrm{L})$, median (range) & $183(0.58-44.2)$ & $122(45.7-1418.2)$ & $289.7(45.7-930.2)$ & 0.016 \\
\hline Highest AST, ( $\mu \mathrm{kat} / \mathrm{L})$, median (range) & $1.8(0.3-258.8)(n=98)$ & $1.6(0.3-249)(n=59)$ & $2.6(0.3-258.8)(n=39)$ & 0.033 \\
\hline Highest ALT, $(\mu \mathrm{kat} / \mathrm{L})$, median (range) & $1.5(0.2-78.2)(n=96)$ & $1.5(0.2-78.2)(n=60)$ & $1.6(0.3-65.9)(n=36)$ & 0.226 \\
\hline Highest CRP, $(\mathrm{mg} / \mathrm{L})$, median (range) & $213.6(2-2641)(n=100)$ & $186(2-423.3)(n=59)$ & $258.6(5.97-2641)(n=41)$ & 0.019 \\
\hline Highest creatine kinase, $(\mu \mathrm{kat} / \mathrm{L})$, median (range) & $5.5(0.2-248.5)(n=35)$ & $5.5(0.2-199)(n=20)$ & $5.0(0.7-248.5)(n=15)$ & 0.657 \\
\hline Highest LDH, ( $\mu \mathrm{kat} / \mathrm{L})$, median (range) & $9.8(3-149.4)(n=28)$ & $6.7(2.9-149.4)(n=16)$ & $17.5(4.8-9.5)(n=12)$ & 0.059 \\
\hline Highest myoglobin, (nmol/L), median (range) & $30.3(0.003-8438.8)(n=37)$ & $6.1(0.003-396.1)(n=19)$ & $86.5(5.5-8434.8)(n=18)$ & 0.002 \\
\hline Highest Troponin I, $(\mu \mathrm{g} / \mathrm{L})$, median (range) & $0.2(0.01-80)(n=95)$ & $0.1(0.01-45.6)(n=56)$ & $0.2(0.01-80)(n=39)$ & 0.736 \\
\hline Highest CK-MB, $(\mu$ kat/L), median (range) & $0.09(0.006-13.4)(n=84)$ & $0.07(0.006-2.3)(n=49)$ & $0.2(0.003-13.4)(n=35)$ & 0.007 \\
\hline Highest lactate, $(\mathrm{mmol} / \mathrm{L})$, median (range) & $3.1(0.9-22.5)(n=90)$ & $2.7(0.9-15)(n=54)$ & $4.3(1.0-22.5)(n=36)$ & $<0.001$ \\
\hline $\begin{array}{l}\text { The time interval from presentation to measurement of } \\
\text { highest lactate, day, median (range) }\end{array}$ & $4(1-51)(n=90)$ & $3(1-51)(n=54)$ & $4(1-30)(n=36)$ & 0.606 \\
\hline $\begin{array}{c}\text { Positive of BAL galactomannan test, } N / \text { total } N(\%) \\
\text { (reference }>0.5 \text { index) }\end{array}$ & $2 / 6(33.3)$ & $0 / 1(0)$ & $2 / 5(40)$ & $>0.99$ \\
\hline $\begin{array}{l}\text { Positive of serum galactomannan test, } N / \text { total } N(\%) \\
\text { (reference }>0.5 \text { index) }\end{array}$ & $5 / 23(21.7)$ & 2/11 (18.2) & $3 / 12(25)$ & $>0.99$ \\
\hline Positive of urine legionella $\mathrm{Ag}, \mathrm{N} /$ total $N(\%)$ & $0 / 60$ & $0 / 36$ & $0 / 24$ & - \\
\hline Positive of urine streptococcus $\mathrm{Ag}, \mathrm{N} /$ total $N(\%)$ & $3 / 41(7.3)$ & $3 / 25(12)$ & $0 / 16(0)$ & 0.268 \\
\hline
\end{tabular}

ALT, Alanine aminotransferase; AST, Aspartate aminotransferase; Ag, Antigen; BAL, Bronchial alveolar lavage; BUN, blood urea nitrogen; CRP, C-reactive protein; CK-MB, Creatine kinase-MB isoenzyme; LDH, Lactate dehydrogenase; WBC, White blood cell. 
Table 4. In-hospital complications of patients with severe influenza.

\begin{tabular}{|c|c|c|c|c|}
\hline Variable & Overall $(n=102)$ & Survivors $(n=61)$ & Nonsurvivors $(n=41)$ & $p$ \\
\hline Acute respiratory failure & $99(97)$ & $58(95.1)$ & $41(100)$ & $>0.99$ \\
\hline $\begin{array}{l}\text { Time from onset illness to respiratory failure, day, } \\
\text { median (range) }\end{array}$ & $4(1-27)(n=99)$ & $3.5(1-16)(n=58)$ & $4(1-27)$ & 0.451 \\
\hline $\begin{array}{l}\text { Time from hospital presentation to respiratory } \\
\text { failure, day, median (range) }\end{array}$ & $1(1-21)(n=99)$ & $1(1-13)(n=58)$ & $1(1-21)$ & 0.921 \\
\hline Use of invasive mechanical ventilator & $90(88.2)$ & $52(85.2)$ & $38(92.7)$ & 0.352 \\
\hline $\begin{array}{l}\text { Duration of invasive mechanical ventilation, day, } \\
\text { median (range) }\end{array}$ & $14(1-60)(n=90)$ & $17(3-60)(n=52)$ & $9.5(1-46)(n=38)$ & 0.042 \\
\hline Acute kidney injury & $67(65.7)$ & $34(55.7)$ & $33(80.5)$ & 0.011 \\
\hline Renal replacement therapy & $25(24.5)$ & $11(18)$ & $14(34.1)$ & 0.099 \\
\hline Pneumothorax & $13(12.7)$ & $4(6.6)$ & $9(22)$ & 0.033 \\
\hline Acute respiratory distress syndrome & $52(51)$ & $25(41)$ & $27(65.9)$ & 0.016 \\
\hline Pneumonia & $96(94.1)$ & $57(93.4)$ & $39(95.1)$ & $>0.99$ \\
\hline Pulmonary edema & $3(2.9)$ & $3(4.9)$ & 0 & 0.272 \\
\hline Meningoencephalitis & $2(2)$ & $1(1.6)$ & $1(2.4)$ & $>0.99$ \\
\hline Intracranial hemorrhage & $1(1)$ & 0 & $1(2.4)$ & 0.402 \\
\hline Gastrointestinal bleeding & $36(35.3)$ & $15(24.6)$ & $21(51.2)$ & 0.011 \\
\hline Fulminant hepatitis & $9(8.8)$ & $6(9.8)$ & $3(7.3)$ & 0.737 \\
\hline Rhabdomyolysis & $12(11.8)$ & $5(8.2)$ & $7(17.1)$ & 0.216 \\
\hline Bacteremia & $17(16.7)$ & $11(64.7)$ & $6(35.3)$ & $>0.99$ \\
\hline Bacteremia onset $\geq 48 \mathrm{~h}$ after presentation & $12(11.7)$ & $7(11.4)$ & $5(12.1)$ & $>0.99$ \\
\hline Fungemia & $2(2)$ & 0 & $2(4.9)$ & 0.159 \\
\hline ECMO support & $17(16.7)$ & $5(8.2)$ & $12(29.3)$ & 0.017 \\
\hline Duration of ECMO treatment, day, median (range) & $9(3-25)(n=17)$ & $9(5-25)(n=5)$ & $9.5(3-25)(n=12)$ & 0.958 \\
\hline
\end{tabular}

Data expressed as number (\%) unless otherwise indicated. ECMO, Extra-corporeal membrane oxygenation. 
Extracorporeal membrane oxygenation (ECMO) was initiated for the treatment of refractory hypoxemia, hypercapnia, or both, which occurred despite invasive mechanical ventilation. Seventeen (median age 58 years; range, 24-65) patients with severe influenza-associated ARDS were treated with ECMO, of whom 15 (88.2\%) patients had influenza A virus and $2(11.7 \%)$ had influenza B virus infection. The median duration of ECMO support was nine (range, 9-25) days. Of the 17 patients with influenza-associated ARDS who received ECMO treatment, $12(70.5 \%)$ died. In the 12 patients who died, acute kidney injury $(n=10)$, gastrointestinal bleeding $(n=8)$, rhabdomyolysis $(n=4)$, pneumothorax $(n=2)$, intracranial hemorrhage $(n=1)$, and fulminant hepatitis $(\mathrm{n}=1)$ were the most common conditions contributing to death.

Among the 17 bacteremia patients, five (29.4\%) patients had bacteremia (Staphylococcus aureus in 3, Pseudomonas aeruginosa in one, and Actinomyces oris and Streptococcus salivarius in one) within $48 \mathrm{~h}$ after hospitalization. Twelve patients experienced bacteremia after $48 \mathrm{~h}$ admission including Staphylococcus aureus $(n=3)$, Enterococcus species $(n=3)$, Stenotrophomonas maltophilia $(n=2)$, viridans streptococcus $(n=1)$, and Acinetobacter pittii $(n=1)$. Staphylococcus aureus $(35.3 \%)(16.7 \%$ were methicillin resistant) and Enterococcus species (17.6\%) were the most frequently isolated bacteria from blood cultures.

\subsection{Outcomes}

Of the 102 patients, 41 (median age, 61 [range, 24-93] years) died, with an overall mortality rate of $40.1 \%$. The median duration of illness before death was 18.5 (range, 2-53) days. Nine patients (21.9\%) died within seven days after symptom onset. Of 41 deceased patients, $80.5 \%$ had influenza A virus and $19.5 \%$ had influenza $B$ virus infection. Of the 38 deceased patients who received oseltamivir treatment, $76.3 \%$ of patients received oseltamivir more than $48 \mathrm{~h}$ after onset of the illness (Table 4 ). Among the 41 deceased patients, pneumonia developed in 39 (95.1\%) patients, acute kidney injury in $33(80.5 \%)$, ARDS in $27(65.9 \%)$, gastrointestinal bleeding in $21(51.2 \%)$, and bacteremia in $6(35.3 \%)$ patients (Table 4).

\subsection{Comparison of Survivors and Nonsurvivors}

Compared with survivors, nonsurvivors had a significantly shorter length of hospital stay. Upon hospital admission, elevation of myoglobin and creatine kinase-MB isoenzyme levels was significantly associated with mortality. Moreover, a significantly higher white blood cell count and high creatinine, aspartate aminotransferase, C-reactive protein, myoglobin, creatine kinase-MB isoenzyme, and lactate concentrations, in addition to lower platelet count during the course of hospitalization, were reported in nonsurvivors. Nonsurvivors received ECMO treatment and had a significantly higher incidence of acute kidney injury, pneumothorax, ARDS, and gastrointestinal bleeding than survivors. Multivariate analysis showed that high lactate level during hospitalization (adjusted odds ratio [aOR]: 1.041; 95\% confidence interval [CI]: 1.019-1.064; $p<0.001$ ), ARDS (aOR: 10.098; 95\% CI: 2.505-40.714; $p=0.001$ ), acute kidney injury (aOR: 9.019; 95\% CI: 1.804-45.089; $p=0.007$ ), and gastrointestinal bleeding (aOR: 3.828; 95\% CI: 1.180-12.415; $p=0.025$ ) were independent predictors of mortality in critically ill influenza patients (Table 5).

Table 5. Multivariate analysis of independent risk factors associated with fatality in patients with critically ill influenza.

\begin{tabular}{cccc}
\hline & Odds Ratio & 95\% Confidence Interval & $p$ \\
\hline High blood lactate levels & 1.041 & $1.019-1.064$ & $<0.001$ \\
Adult respiratory & 10.098 & $2.505-40.714$ & 0.001 \\
distress syndrome & 9.019 & $1.804-45.089$ & 0.007 \\
Acute kidney injury & 3.828 & $1.180-12.415$ & 0.025 \\
Gastrointestinal bleeding & & & \\
\hline
\end{tabular}




\subsection{Event-Based Algorithm}

The median highest lactate values (reference value $<2.1 \mathrm{mmol} / \mathrm{L}$ ) and median time from presentation to the highest lactate level among survivors and nonsurvivors were $2.7 \mathrm{mmol} / \mathrm{L}$ and $4.3 \mathrm{mmol} / \mathrm{L}$ and three days and four days, respectively. We selected the lactate variable in multivariate analyses and plotted the ROC curve to identify the optimal cutoff value for predicting mortality. The optimal cutoff of lactate level for predicting mortality was $3.7 \mathrm{mmol} / \mathrm{L}$ with an area under curve of 0.728 , and the sensitivity and specificity of this cutoff were estimated at $63.9 \%$ and $74.1 \%$, respectively (Figure 1). We then created an event-associated algorithm that included lactate level and ARDS-the two variables that were independently and significantly associated with death in multivariate analyses (Figure 2). Fifteen (75.0\%) of the 20 patients with lactate levels of $3.7 \mathrm{mmol} / \mathrm{L}$ or above and with ARDS died, compared with only one (7.7\%) of 13 patients with lactate levels below $2.1 \mathrm{mmol} / \mathrm{L}$ and without ARDS $(p<0.001)$ and $1(10 \%)$ of 10 patients with lactate levels between $2.1 \mathrm{mmol} / \mathrm{L}$ and $3.7 \mathrm{mmol} / \mathrm{L}$ and without ARDS $(p<0.001)$.

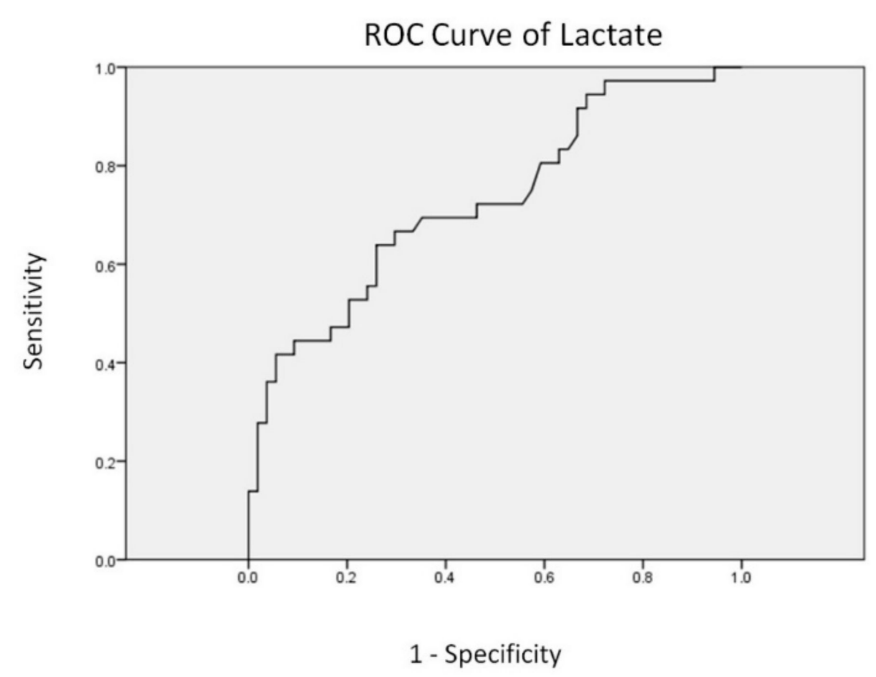

Figure 1. Receiver operating characteristic curve of lactate for prediction of mortality.

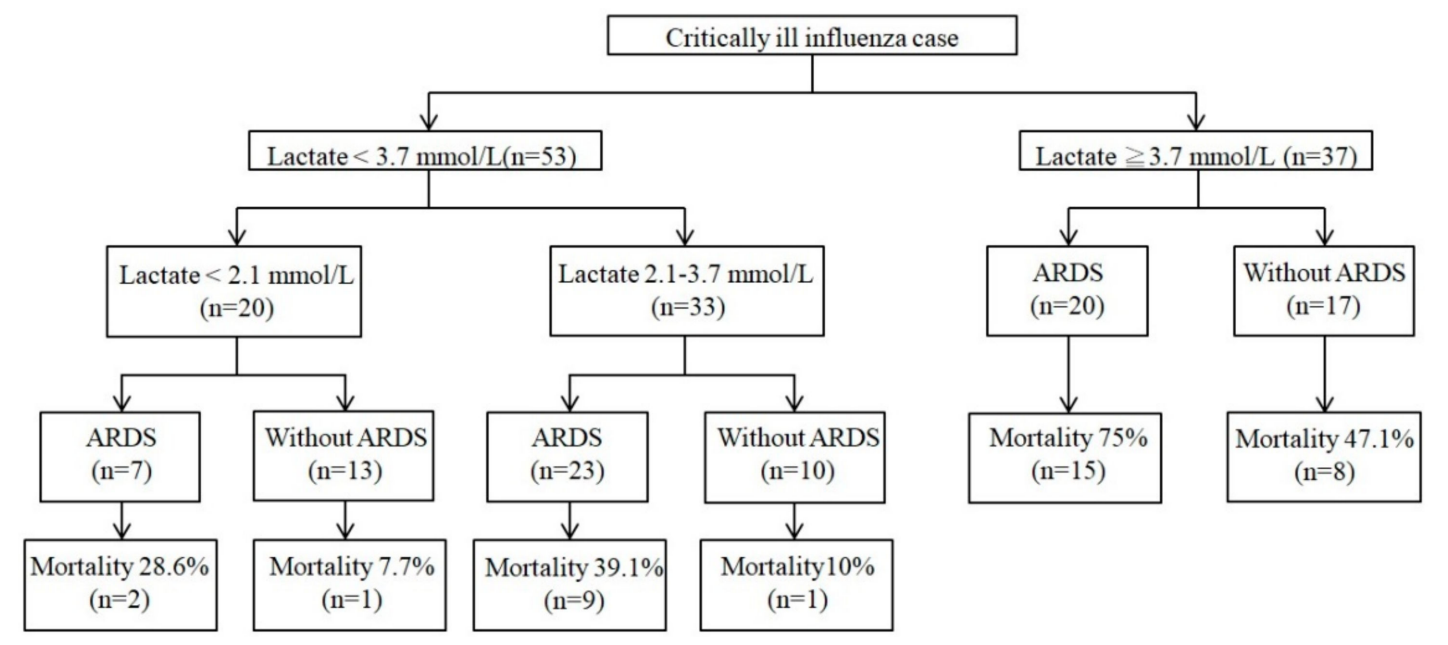

Figure 2. Event-based algorithm.

\section{Discussion}

In a study involving 444 adult patients with influenza in hospitals in the United States, the mortality rate was 20.9\% [21]. Furthermore, a mortality rate of $20.6 \%$ was reported by Francisco et al. in their study of 2059 patients admitted to ICUs for influenza infection [22]. In our study, a mortality rate as high as $40 \%$ was found in 102 critically ill adult patients with influenza. However, which 
variables can predict poor patient outcomes after influenza virus infection remain to be elucidated. In the present study, our dataset included clinical signs and symptoms and laboratory results at presentation and the entire course of hospitalization as well as complications during the clinical course. We determined which demographic, clinical, and laboratory findings were associated with death that could help clinicians deliver timely and sufficient treatment to critically ill influenza patients. Our results underscore that high blood lactate levels during hospitalization, ARDS, acute kidney injury, and gastrointestinal bleeding were independent risk factors of mortality in critically ill influenza patients.

High blood lactate levels indicate tissue hypoxia due to increased lactate generation via anaerobic glycolysis [23]. High blood lactate levels have been correlated with poor outcomes in patients with bacterial sepsis and septic shock [24]. In the present study, high blood lactate levels were found to be significantly and independently associated with fatal outcomes in critically ill influenza patients. In addition, nonsurvivors had a significantly higher prevalence of acute kidney injury and gastrointestinal bleeding and received ECMO treatment in our series. Importantly, acute kidney injury and gastrointestinal bleeding have been shown to be independent risk factors of mortality. We believe that these complications are caused by clinicians' lack of awareness of early detection of organ hypoperfusion. As patients in early phases of hypoperfusion do not always show obvious clinical signs, blood lactate level may be an important marker for this disorder. Thus, timely recognition of organ hypoperfusion and initiation of effective volume replacement to reverse tissue hypoxia are critical steps in preventing mortality and morbidity. Notably, the median time interval from patient arrival to measurement of highest blood lactate was four days in nonsurvivors in our series. Further, the median time from illness onset to fatality was 18.5 days. This finding indicates that blood lactate levels can be a useful early marker assisting clinicians in predicting the outcomes in critically ill influenza patients.

Our series here showed gastrointestinal bleeding occurred in one-third of included patients and more than half of them with fatal outcome. Stress ulcer prophylaxis for critically ill patients is not universally practiced in our series. The causes of gastrointestinal bleeding in these patients are multifactorial. Our study underlines that clinicians should be alert to possible gastrointestinal bleeding when caring for a critically ill influenza patient because this complication potentially leads to death if it is not recognized early and treated accordingly.

ARDS is a lethal complication of influenza infection [25]. Ortiz et al. estimated that the incidence of influenza-associated acute respiratory failure was 2.7 events per 100,000 person-years [26]. In a study of 58 patients with ARDS, 28 (48.2\%) were due to influenza virus infection, and $32.1 \%$ of the patients with influenza-associated ARDS received ECMO treatment [27]. Davies et al. reported that the incidence of pdm09 A/H1-associated ARDS sufficient to warrant consideration of ECMO was estimated at 2.6 cases per million population [28]. ARDS is an independent risk factor for hospital mortality in critically ill influenza patients, and the mortality rate can be as high as $52 \%$ [29]. The present study results are consistent with previous findings wherein $97 \%$ of critically ill influenza patients developed acute respiratory failure with a median time of four days between illness onset and respiratory failure, and $51 \%$ of them subsequently developed ARDS during their clinical course. In addition, approximately one-third of the patients with influenza-associated ARDS required ECMO for profound hypoxemic respiratory failure. Our study highlights that severe oxygenation failure occurred rapidly after hospital admission and that clinicians should not delay delivering appropriate rescue therapies as well as deploying ICU resources to meet this treatment requirement, particularly during the influenza epidemic.

In the present study, we established a simple event-associated algorithm including blood lactate level and ARDS for timely detection of critically ill influenza patients who are at greater risk of mortality. Notably, critically ill influenza patients without ARDS but with a blood lactate concentration of $3.7 \mathrm{mmol} / \mathrm{L}$ had an in-hospital mortality of $47.1 \%$, and more importantly, the mortality rate increased to $75 \%$ for those with high blood lactate $(\geq 3.7 \mathrm{mmol} / \mathrm{L}$ ) and those that developed ARDS. In contrast, only $7.7 \%$ of critically ill influenza patients without ARDS and with normal blood lactate levels died. Considering the high mortality rate among critically ill influenza patients, this event-based algorithm 
could aid in the timely decision-making process and provision of prompt intensive care for patients with potentially fatal outcomes, particularly in resource-limited areas; some key laboratory tests such as blood lactate might be of greater value than others when allocating limited healthcare resources.

Previous studies have shown that early administration of an antiviral agent is associated with a shorter duration and reduced severity of illness [14-16]. Greater benefits were shown with early treatment initiated within two days after the onset of illness [30-32]. In our study, the median time from illness onset to hospital presentation was three days and more than two-thirds of the patients received delayed ( $48 \mathrm{~h}$ after illness onset) antiviral treatment. Although the provision of antiviral therapy between survivors and nonsurvivors did not differ significantly in our series, the importance of early treatment with antivirals in critically ill influenza patients cannot be overemphasized.

In our study, bacteremia was detected in 17 critically ill adult patients. Importantly, five of them acquired bacteremia within $48 \mathrm{~h}$ after hospitalization, and in three cases, the infection was caused by Staphylococcus aureus. A report of the 2009-2010 influenza pandemic among critically ill children revealed that nearly $5 \%$ of the patients had bacteremia within $72 \mathrm{~h}$ and Staphylococcus aureus was the most frequently isolated bacterium, which contributed to the death rate in the current pandemic [33]. In a study of 32 influenza-positive patients (including pediatric and adult patients), poor outcomes were found among patients who were coinfected with influenza viruses and Staphylococcus aureus [34]. Although we were unable to conclude whether or not initiating timely additional antimicrobial treatment in critically ill influenza patients led to better clinical outcomes, our findings and previous reports underscore that Staphylococcus aureus remains the most important cause of bacterial coinfection in pediatric and adult influenza patients.

Invasive pulmonary Aspergillus as a coinfection in patients with severe influenza has been described [35-37]. In a cohort study involving seven ICUs over a period of seven influenza seasons showed that influenza and the use of corticosteroids were independent risk factors for invasive aspergillosis [35]. In the present study, invasive pulmonary aspergillosis was confirmed in two deceased influenza patients with high galactomannan index in bronchoalveolar lavage fluid. This finding emphasizes that clinicians should be aware of the risk of invasive aspergillosis in critically ill influenza patients, particularly immunocompromised patients or those receiving corticosteroids. Further studies are needed to understand the incidence, risk factors, and clinical features of invasive pulmonary aspergillosis in influenza patients.

In 2003, an avian influenza virus of H5N1 subtype was isolated from a smuggled duck in Kinmen Island of Taiwan [38]. However, no locally acquired H5N1 disease in humans had been reported in Taiwan [39]. Thus, none of the patients in this series tested positive for H5N1.

This study has several potential limitations. First, given the retrospective nature of the study, information on vaccination status, including pneumococcus and influenza, and some missing laboratory data such as pneumonia severity index and coagulation profile, were not collected. Second, the study population comprised adult patients; therefore, the results cannot be generalized to pediatric patients. However, the strengths of this study include a detailed description of clinical and laboratory information at presentation and the entire hospitalization course of critically ill patients with influenza. We highlighted the key factors associated with poor outcomes for critically ill influenza patients and established a decision-making algorithm that can take advantage of simple clinical and laboratory evaluations.

\section{Conclusions}

We identified clinical and laboratory predictors of mortality that could aid in the prediction of the poor outcomes in hospitalized critically ill influenza patients, as timely intensive supportive care might be lifesaving. Medical services and ICUs can be overwhelmed during the peak of influenza epidemics, particularly in point-of-care resource-limited areas. Our findings could substantially assist with allocation of resources in the selection of the main key clinical data in primary care at the initial clinical evaluation of critically ill influenza patients. 
Author Contributions: I.-K.L. made substantial contributions to the conception, study design, data analysis and interpretation, and drafting, editing, and submitting the manuscript. J.-C.H. made substantial contributions to the data collection, data analysis, and writing the manuscript. W.-C.H., Y.-C.C., and C.-Y.T. contributed to the design of the study and interpreted the findings. All authors have read and agreed to the published version of the manuscript.

Funding: This study was supported by a grant (document no. CMRPG8H0241 to I.-K.L.) from Kaohsiung Chang Gung Memorial Hospital, Kaohsiung, Taiwan. The funder had no role in study design, data collection and analysis, decision to publish, or preparation of the manuscript.

Acknowledgments: We thank the staff members in the Intensive Care Units of Kaohsiung Chang Gung Memorial Hospital for the management of patients.

Conflicts of Interest: The authors declare no conflicts of interest.

\section{References}

1. Nicholson, K.G.; Wood, J.M.; Zambon, M. Influenza. Lancet 2003, 362, 1733-1745. [CrossRef]

2. Thompson, W.W.; Shay, D.K.; Weintraub, E.; Brammer, L.; Bridges, C.B.; Cox, N.J.; Fukuda, K. Influenza-associated hospitalizations in the United States. JAMA 2004, 292, 1333-1340. [CrossRef] [PubMed]

3. Centers for Disease Control and Prevention (CDC). Estimates of deaths associated with seasonal influenza-United States, 1976-2007. MMWR. Morb. Mortal. Wkly. Rep. 2010, 59, 1057-1062.

4. World Health Organization (WHO). Influenza (Seasonal). Available online: https://www.who.int/newsroom/fact-sheets/detail/influenza (accessed on 12 January 2020).

5. Iuliano, A.D.; Roguski, K.M.; Chang, H.H.; Muscatello, D.J.; Palekar, R.; Tempia, S.; Cohen, C.; Gran, J.M.; Schanzer, D.; Cowling, B.J.; et al. Estimates of global seasonal influenza-associated respiratory mortality: A modelling study. Lancet 2018, 391, 1285-1300. [CrossRef]

6. Dawood, F.S.; Jain, S.; Finelli, L.; Shaw, M.W.; Lindstrom, S.; Garten, R.J.; Gubareva, L.V.; Xu, X.; Bridges, C.B.; Uyeki, T.M. Novel Swine-Origin Influenza A (H1N1) Virus Investigation Team. Emergence of a novel swine origin influenza A (H1N1) virus in humans. N. Engl. J. Med. 2009, 360, 2605-2615. [CrossRef]

7. Shrestha, S.S.; Swerdlow, D.L.; Borse, R.H.; Prabhu, V.S.; Finelli, L.; Atkins, C.Y.; Owusu-Edusei, K.; Bell, B.; Mead, P.S.; Biggerstall, M.; et al. Estimating the burden of 2009 pandemic influenza A (H1N1) in the United States (April 2009-April 2010). Clin. Infect. Dis. 2011, 52, S75-S82. [CrossRef]

8. Zhou, F.; Li, H.; Gu, L.; Liu, M.; Xue, C.X.; Cao, B.; Wang, C. Risk factors for nosocomial infection among hospitalised severe influenza A(H1N1)pdm09 patients. Respir. Med. 2018, 134, 86-91. [CrossRef]

9. Paddock, C.D.; Liu, L.; Denison, A.M.; Bartlett, J.H.; Holman, R.C.; Deleon-Carners, M.; Emery, S.L.; Drew, C.P.; Shieh, W.J.; Uyeki, T.M. Myocardial injury and bacterial pneumonia contribute to the pathogenesis of fatal influenza B virus infection. J. Infect. Dis. 2012, 205, 895-905. [CrossRef]

10. Daoud, A.; Laktineh, A.; Macrander, C.; Mushtaq, A.; Soubani, A.O. Pulmonary complications of influenza infection: A targeted narrative review. Postgrad. Med. 2019, 131, 299-308. [CrossRef]

11. Kumar, A.; Zarychanski, R.; Pinto, R.; Cook, D.J.; Marshall, J.; Lacroix, J.; Stelfox, T.; Bagshaw, S.; Choong, K.; Lamontagne, F. Canadian Critical Care Trials Group H1N1 Collaborative. Critically ill patients with 2009 influenza A (H1N1) infection in Canada. JAMA 2009, 302, 1872-1879. [CrossRef]

12. Rello, J.; Rodríguez, A.; Ibañez, P.; Socias, L.; Cebrian, J.; Marques, A.; Guerrero, J.; Ruiz-Santana, S.; Marquez, E.; Nogel-Saez, F.D. H1N1 SEMICYUC Working Group. Intensive care adult patients with severe respiratory failure caused by Influenza A (H1N1)v in Spain. Crit. Care 2009, 13, R148. [CrossRef] [PubMed]

13. Domínguez-Cherit, G.; Lapinsky, S.E.; Macias, A.E.; Pinto, R.; Espinosa-Perez, L.; de la Torre, A.; Poblano-Morales, M.; Baltazar-Torres, J.A.; Bautista, E.; Martinez, A. Critically Ill patients with 2009 influenza A(H1N1) in Mexico. JAMA 2009, 302, 1880-1887. [CrossRef] [PubMed]

14. Dobson, J.; Whitley, R.J.; Pocock, S.; Monto, A.S. Oseltamivir treatment for influenza in adults: A meta analysis of randomised controlled trials. Lancet 2015, 385, 1729-1737. [CrossRef]

15. Doll, M.K.; Winters, N.; Boikos, C.; Kraicer-Melamed, H.; Gore, G.; Quach, C. Safety and effectiveness of neuraminidase inhibitors for influenza treatment, prophylaxis, and outbreak control: A systematic review of systematic reviews and/or meta analyses. J. Antimicrob. Chemother. 2017, 72, 2990-3007. [CrossRef] [PubMed] 
16. Fry, A.M.; Goswami, D.; Nahar, K.; Sharmin, A.T.; Rahman, M.; Gubareva, L.; Azim, T.; Bresee, J.; Luby, S.P.; Brooks, W.A. Efficacy of oseltamivir treatment started within 5 days of symptom onset to reduce influenza illness duration and virus shedding in an urban setting in Bangladesh: A randomised placebo-controlled trial. Lancet Infect. Dis. 2014, 14, 109-118. [CrossRef]

17. ARDS Definition Task Force; Ranieri, V.M.; Rubenfeld, G.D.; Thompson, B.T.; Ferguson, N.D.; Caldwell, E.; Fan, E.; Camporota, L.; Slutsky, A.S. Acute Respiratory Distress Syndrome. JAMA 2012, 307, 2526-2533. [CrossRef]

18. Steiner, I.; Budka, H.; Chaudhuri, A.; Koskiniemi, M.; Sainio, K.; Salonen, O.; Kennedy, P.G. Viral meningoencephalitis: A review of diagnostic methods and guidelines for management. Eur. J. Neurol. 2010, 17, e57. [CrossRef]

19. Heer, K.D.; Gerritsen, M.G.; Visser, C.E.; Leeflang, M.M. Galactomannan detection in broncho-alveolar lavage fluid for invasive aspergillosis in immunocompromised patients. Cochrane Database Syst. Rev. 2019. [CrossRef]

20. Maertens, J.; Theunissen, K.; Verbeken, E.; Lagrou, K.; Verhaegen, J.; Boogaerts, M.; Eldere, J.V. Prospective clinical evaluation of lower cut-offs for galactomannan detection in adult neutropenic cancer patients and haematological stem cell transplant recipients. Br. J. Haematol. 2004, 126, 852-860. [CrossRef]

21. Shah, N.S.; Greenberg, J.A.; McNulty, M.C.; Gregg, K.S.; Riddell, J.; Mangino, J.E.; Weber, D.M.; Hebert, C.L.; Marzec, N.S.; Barron, M.A.; et al. Severe Influenza in 33 US Hospitals, 2013-2014: Complications and Risk Factors for Death in 507 Patients. Infect. Control Hosp. Epidemiol. 2015, 36, 1251-1260. [CrossRef]

22. Álvarez-Lerma, F.; Marín-Corral, J.; Vila, C.; Masclans, J.R.; González de Molina, F.J.; Martín Loeches, I.; Barbadillo, S.; Rodríguez, A. H1N1 GETGAG/SEMICYUC Study Group. Delay in diagnosis of influenza A (H1N1)pdm09 virus infection in critically ill patients and impact on clinical outcome. Crit. Care 2016, 20. [CrossRef]

23. Fall, P.J.; Szerlip, H.M. Lactic Acidosis: From Sour Milk to Septic Shock. J. Intensive Care Med. 2005, 20, 255-271. [CrossRef]

24. Mikkelsen, M.E.; Miltiades, A.N.; Gaieski, D.F.; Goyal, M.; Fuchs, B.D.; Shah, C.V.; Bellamy, S.L.; Christie, J.D. Serum lactate is associated with mortality in severe sepsis independent of organ failure and shock. Crit. Care Med. 2009, 37, 1670-1677. [CrossRef] [PubMed]

25. Short, K.R.; Kroeze, E.; Fouchier, R.; Kuiken, T. Pathogenesis of influenza-induced acute respiratory distress syndrome. Lancet Infect. Dis. 2014, 14, 57-69. [CrossRef]

26. Ortiz, J.R.; Neuzil, K.M.; Rue, T.C.; Zhou, H.; Shay, D.K.; Cheng, P.Y.; Cooke, C.R.; Goss, C.H. Population-based Incidence Estimates of Influenza-associated Respiratory Failure Hospitalizations, 2003 to 2009. Am. J. Respir. Crit. Care Med. 2013, 188, 710-715. [CrossRef]

27. Yoo, J.W.; Ju, S.; Lee, S.J.; Cho, M.C.; Cho, Y.J.; Jeong, Y.Y.; Lee, J.D.; Kim, H.C. Characteristics and Outcomes of Patients with Pulmonary Acute Respiratory Distress Syndrome Infected with Influenza versus Other Respiratory Viruses. Tuberc. Respir. Dis. 2019, 82, 328. [CrossRef]

28. Davies, A.; Jones, D.; Bailey, M.; Beca, J.; Bellomo, R.; Blackwell, N.; Forrest, P.; Gattas, D.; Granger, E. Extracorporeal Membrane Oxygenation for 2009 Influenza A(H1N1) Acute Respiratory Distress Syndrome. JAMA 2009, 302, 1888-1895. [CrossRef]

29. Li, G.; Yilmaz, M.; Kojicic, M.; Fernández-Pérez, E.; Wahab, R.; Huskins, W.C.; Afessa, B.; Truwit, J.D.; Gajic, O. Outcome of critically ill patients with influenza virus infection. J. Clin. Virol. 2009, 46, 275-278. [CrossRef]

30. Jain, S.; Kamimoto, L.; Bramley, A.M.; Schmitz, A.M.; Benoit, S.R.; Louie, J.; Sugerman, D.E.; Druckenmiller, J.K.; Ritger, K.A.; Chugh, R. Hospitalized Patients with 2009 H1N1 Influenza in the United States, April-June 2009. N. Engl. J. Med. 2009, 361, 1935-1944. [CrossRef]

31. Hanshaoworakul, W.; Simmerman, J.M.; Narueponjirakul, U.; Sanasuttipun, W.; Shinde, V.; Kaewchana, S.; Areechokechai, D.; Levy, J.; Ungchusak, K. Severe Human Influenza Infections in Thailand: Oseltamivir Treatment and Risk Factors for Fatal Outcome. PLoS ONE 2009, 4. [CrossRef]

32. Kumar, A. Early versus late oseltamivir treatment in severely ill patients with 2009 pandemic influenza A (H1N1): Speed is life. J. Antimicrob. Chemother. 2011, 66, 959-963. [CrossRef] [PubMed]

33. Randolph, A.G.; Vaughn, F.; Sullivan, R.; Rubinson, L.; Thompson, B.T.; Yoon, G.; Smoot, E.; Rice, T.W.; Loftis, L.L.; Helfaer, M.; et al. Critically ill children during the 2009-2010 influenza pandemic in the United States. Pediatrics 2011, 128, e1450-e1458. [CrossRef] [PubMed] 
34. McDanel, J.S.; Perencevich, E.N.; Storm, J.; Diekema, D.J.; Herwaldt, L.; Johnson, J.K.; Winokur, P.L.; Schweizer, M.L. Increased Mortality Rates Associated withStaphylococcus aureusand Influenza Co-infection, Maryland and Iowa, USA. Emerg. Infect. Dis. 2016, 22, 1253-1256. [CrossRef] [PubMed]

35. Schauwvlieghe, A.; Rijnders, B.; Philips, N.; Verwijs, R.; Vanderbeke, L.; Van Tienen, C.; Lagrou, K.; Verweij, P.E.; Van de Veerdonk, F.L.; Gommers, D.; et al. Invasive aspergillosis in patients admitted to the intensive care unit with severe influenza: A retrospective cohort study. Lancet Respir. Med. 2018, 6, 782-792. [CrossRef]

36. Wauters, J.; Baar, I.; Meersseman, P.; Meersseman, W.; Dams, K.; De Paep, R.; Lagrou, K.; Wilmer, A.; Jorens, P.; Hermans, G.; et al. Invasive pulmonary aspergillosis is a frequent complication of critically ill H1N1 patients: A retrospective study. Intensive Care Med. 2012, 38, 1761-1768. [CrossRef] [PubMed]

37. Van de Veerdonk, F.L.; Kolwijck, E.; Lestrade, P.P.; Hodiamont, C.J.; Rijnders, B.J.; van Paassen, J.; Haas, P.J.; Dos Santos, C.O.; Kampinga, G.A.; Bergmans, D.C.; et al. Influenza-associated Aspergillosis in Critically Ill Patients. Am. J. Respir. Crit. Care Med. 2017, 196, 524-527. [CrossRef]

38. Lee, M.S.; Deng, M.C.; Lin, Y.J.; Chang, C.Y.; Shieh, H.K.; Shiau, J.Z.; Huang, C.C. Characterization of an H5N1 avian influenza virus from Taiwan. Vet. Microbiol. 2007, 124, 193-201. [CrossRef]

39. Gong, Y.N.; Kuo, R.L.; Chen, G.W.; Shih, S.R. Centennial review of influenza in Taiwan. Biomed. J. 2018, 41, 234-241. [CrossRef]

(C) 2020 by the authors. Licensee MDPI, Basel, Switzerland. This article is an open access article distributed under the terms and conditions of the Creative Commons Attribution (CC BY) license (http://creativecommons.org/licenses/by/4.0/). 